EESTI NSV TEADUSTE AKADEEMIA TOIMETISED, 28. KOIDE KEEMIA, 1979, NR. 1

ИЗВЕСТИЯ АКАДЕМИИ НАУК ЭСТОНСКОП ССР. ТОМ 28 ХИМИЯ. 1979, № 1

Р. ВЕСКИ, Евгения БОНДАРЬ, А. ФОМИНА

\title{
ОБРАЗОВАНИЕ ВОДОРОДА ПРИ ОКИСЛИТЕЛЬНОЙ ДЕСТРУКЦИИ САПРОПЕЛИТОВ
}

(Представлена О. Эйзеном)

При окислительной деструкции углей молекулярным кислородом в щелочной среде при $270^{\circ} \mathrm{C}$ образуется свободный водород (от 0,7 до 9,1\% от водорода органического вещества - ОВ - угля), что объясняется наличием в структуре угля фрагментов алифатической и алициклической природы, способных к окислительному дегидрированию [ $\left.{ }^{1}\right]$.

По данным [2], при низких значениях О/С имеет место преимущественно окислительно-гидролитическое расщепление с присоединением элементов воды. Далее протекают реакции окислительного дегидрирования с выделением свободного водорода и окислительной ароматизации продуктов расщепления.

Факт образования свободного водорода при окислении гумолитов представляет интерес и для богатых водородом сапропелитов. Имеется упоминание об анализе газов окисления сланца на содержание в них водорода, но не указывается, был ли он определен [3]. Превращение керогена кукерсита при термолизе начинается, согласно [4], уже при $100^{\circ}$, однако за начало его разложения принят интервал $170-180^{\circ}\left[{ }^{5}\right]$; водород выделяется в незначительных количествах в интервале $250-275^{\circ}\left[{ }^{6,7}\right]$ $0,004 \%$ (расчет на основе [6]) и при продолжительном 142-часовом опыте в том же интервале температур - $0,09 \%$ от водорода керогена (расчет на основе [7]). Водород образуется также при нагревании суспензии кукерсита в воде, но в литературе приводятся данные, характеризующие процесс только начиная с $400^{\circ}\left[{ }^{8}\right]$.

\section{Экспериментальная часть}

$\mathrm{C}$ ы р ье. Флотационный концентрат керогена кукерсита из сланца 3-го сорта шахты Кява-2 (Ac 9,5; $\left(\mathrm{CO}_{2}^{\mathrm{c}}\right)_{\text {минер. }}$ 1,6; $\mathrm{C}^{\mathrm{r} 78,6 ;} \mathrm{H}^{\mathrm{r}} 10,0 \%$ и H/C 1,5), будаговский сапропелит Иркутского бассейна (соответственно, $13,3 ; 0,3 ; 77,7 ; 9,9$ и 1,5$)$, горючий сланец Болтышского месторождения Украинской ССР пласта В-2 IV горизонта $(61,2 ; 3,3 ; 74,4 ; 10,6$ и 1,7$)$ и горючий сланец Мандраского месторождения Болгарии $(57,3 ; 13,2 ; 76,3$; 11,0 и 1,7). Измельчение $-0,1$ мм, для мандраского сланца -3 мм (содержал фракции $-1,5$ мм около $50 \%$ ).

А п п р а тура. Четырехлитровый хромоникелевый вращающийся (46 об/мин) автоклав с электрообогревом венгерской фирмы «Лампарт». Ан ализ реакци онных г азов проведен на газовом хроматографе 

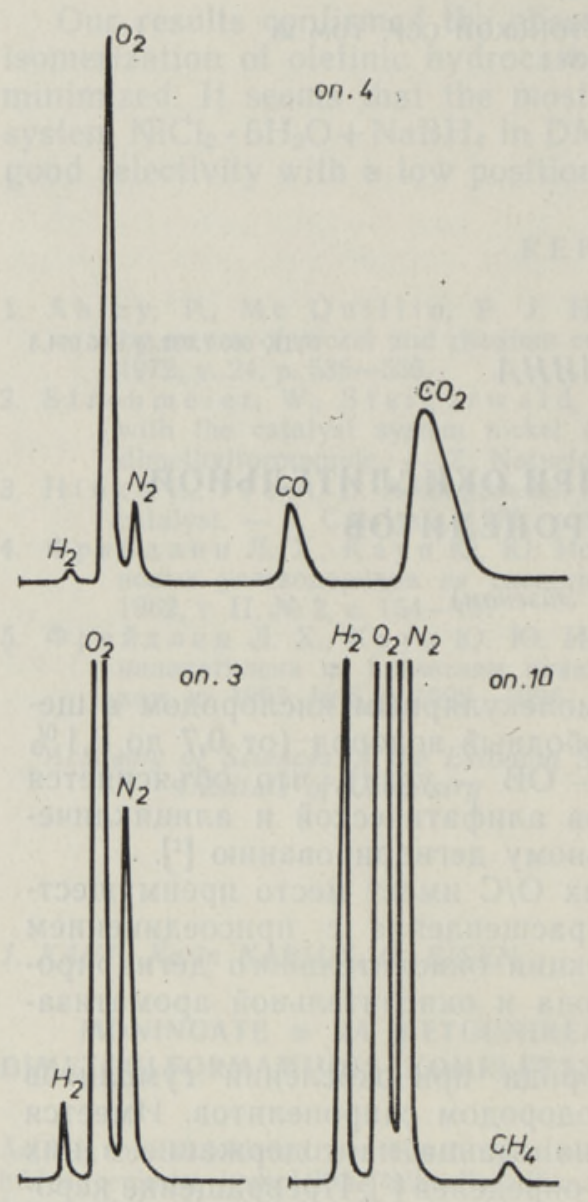

Рнс. 1. Хроматограммы реакционных газов.

УХ-1 Выруского завода газоанализаторов на двух последовательно соединенных колонках с молекулярным ситом $\mathrm{CaA}\left(\mathrm{H}_{2}, \mathrm{O}_{2}, \mathrm{~N}_{2}, \mathrm{CO}\right)$ и активированным углем СКТ с добавкой сквалана $\left(\mathrm{CO}_{2}, \mathrm{CH}_{4}\right)$. Хроматограммы даны на рис. 1 .

Анализ реакционной смеси. Двуокись углерода в нерастворимых и растворимых продуктах окисления определялась по ГОСТ 6381-52, элементный анализ нерастворимых продуктов - по ГОСТ 2408-49.

Условия оки сления приводятся в таблице. Количество кислорода регулировалось степенью заполнения автоклава жидкой фазой (суспензией). С целью удаления азота воздуха начальное давление создавалось при повторном заполнении автоклава кислородом, а в опытах с гелием предварительно азотом.

Опыты 1-8 проведены при оптимальных температурных условиях получения алифатических дикарбоновых кислот из керогена кукерсита [9], а также при температуре $270^{\circ}$, прннятой для окисления гумусовых углей [ $\left.{ }^{1}\right]$.

\section{Обсуждение результатов}

Сопоставление данных таблицы по нагреву керогена кукерсита с водной щелочью в атмосфере гелия (оп. 5 и 12) и по окислению кислородом в водной среде (оп. 4) с данными окислительной деструкции кислородом в щелочной среде (остальные опыты с кукерситом) показывает, что кислород в водно-щелочной среде способствует образованию большего количества свободного водорода. С увеличением расхода молекулярного кислорода увеличивается и количество свободного водорода при нагреве кукерсита и бурого угля Ангренского месторождения, но снижается в опытах с Фан-Ягнобским каменным углем (рис. 2). Расчеты для углей проведены на основе [1] с учетом размеров автоклава и загрузки [10].

Опыты с различными сапропелитами при примерно одинаковых расходах кислорода (таблица, оп. 2,6 и 7) дали отличающиеся выходы свободного водорода в диапазоне $0,17-0,72 \%$. Данных о реакциях с молекулярным кислородом в щелочной среде в изученных температурных пределах как для индивидуальных соединений, так и каустобиолитов, практически не имеется (кроме $\left.\left[1,2,1^{0}\right]\right)$. Обычно описываются процессы щелочного плавления при температурах выше $300^{\circ}\left[^{11}\right]$. Отмечается известная способность древесного угля, кокса, графита и чистого углерода выделять водород при нагревании с едким натром до $350^{\circ}\left[{ }^{12}\right]$. Водород 


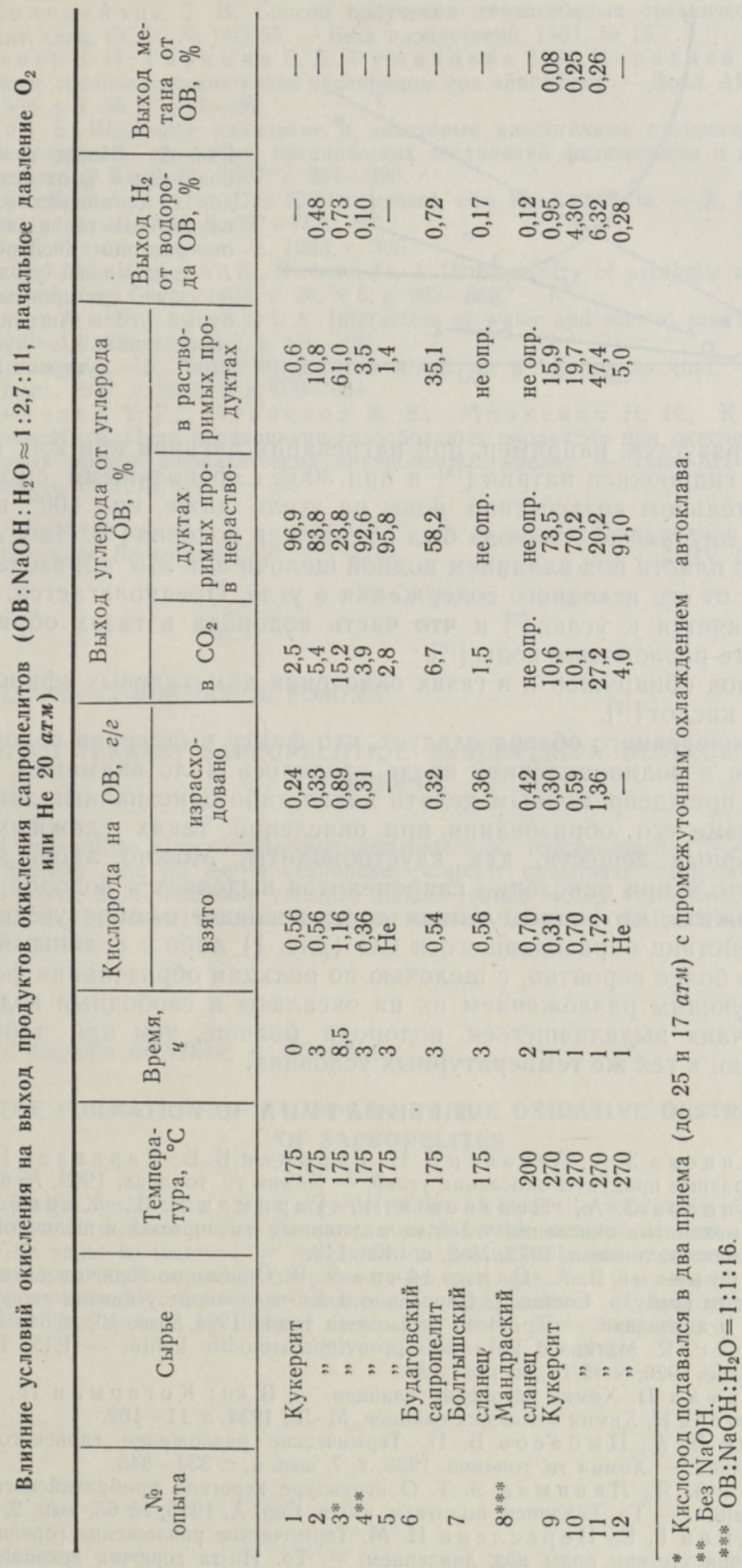




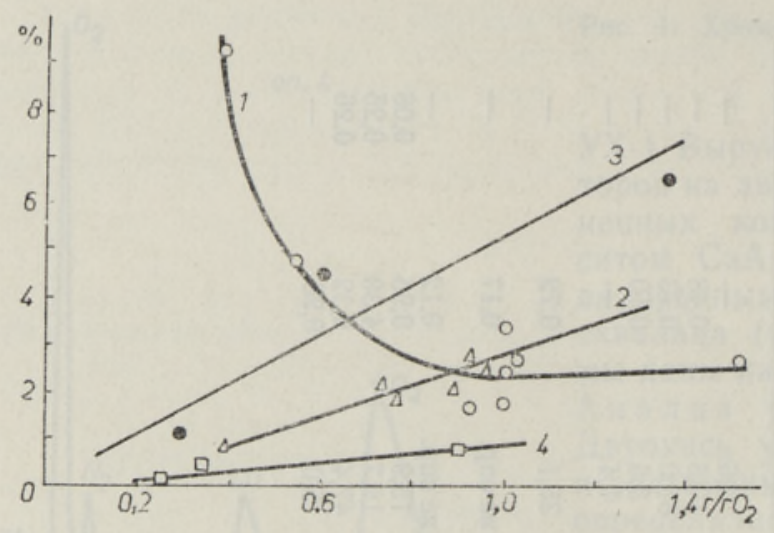

Рис. 2. Выход газообразного водорода в \% от исходного водорода органнческого вещества каустобиолита в зависимости от расхода кислорода (2/2). 1 - каменный уголь Фан-Ягнобского месторождения, 2 бурый уголь Ангренского месторождения, 3 - кукерсит при $270^{\circ} \mathrm{C}, 4-$ кукерсит при $175^{\circ} \mathrm{C}$.

также образуется, например, при нагревании лигнина при $250^{\circ}$ в водном растворе гидроокиси натрия [13] и при $300^{\circ}$ с фенольными смолами [14]. При длительном воздействии воды на уголь даже при $100^{\circ}$ наряду с окисью и двуокисью углерода был обнаружен водород [15]. Из угля питтсбургского пласта под влиянием водной щелочи при $275^{\circ}$ образовалось $4 \%$ водорода от его исходного содержания в угле. Предполагается, что вода присоединяется к углю $\left[{ }^{2}\right]$ и что часть водорода в газах образуется в результате разложения воды [ $\left.{ }^{16}\right]$.

Водород обнаружен и в газах окисления диметиловых эфиров дикарбоновых кислот $\left[{ }^{17}\right]$.

Из приведенного обзора следует, что факту выделения водорода при окислении в водно-щелочной среде уделялось мало внимания. Поэтому было бы преждевременным делать какие-либо однозначные заключения о механизме его образования при окислении таких сложных макромолекулярных веществ, как каустобиолиты. Можно лишь констатировать, что и при окислении сапропелитов выделяется водород, а также предположить, что определенная доля последнего образуется за счет взаимодействия образовавшегося СО (рис. 1) либо с водяными парами, либо, что более вероятно, с щелочью по реакции образования формиатов с последующим разложением их на оксалаты и свободный водород. Во всех случаях выделившегося водорода больше, чем при термической деструкции в тех же температурных условиях.

\section{Л И ТЕРАТ У РА}

1. Румянцев а 3. А., Певзнер 3. И., Га рцман Б. Б., Кар а в аев Н. М. Газообразные продукты окнсления углей. - Химия тв. топлива, 1969, № 6, с. 11-17.

2. Р умянцева 3. А., Певзне р 3. И., Гарцман Б. Б., Кар ава ев Н. М. О механизме окисления углей молекулярным кислородом в щелочной среде. Химия тв. топлива, 1972, № 2, с. 146-149.

3. Проскуряков В. А., Солов ей чик 3. В. Окисление горючих сланцев кислородом воздуха. Сообщ. І. Окисление водно-щелочной суспензии гдовского сланца в автоклаве. - Тр. Всес. н.-н. ин-та топл., 1961, вып. 10, с. $64-80$.

4. J a n n s e n, R. Märkused kukersiidi proovimismeetodite kohta. - ETS Tehn. Ringvaade, 1920 , N 15/16, lk. 113-120.

5. К огер м ан П. Химия эстонских сланцев. - В кн.: Когерм ан П., Л ю т с К., Х ю с с е И. Химия эстонских сланцев. М.-Л., 1934, с. 11-102.

6. Л ан ин В. А., Цы ба сов В. П. Термическое разложение гдовского горючего сланца. - Химня тв. топлива, 1936, т. 7, вып. 4, с. $334-346$.

7. А а рна А. Я., Л и п п а а Э. Т. О структуре керогена прибалтнйского горючего сланца. - Тр. Таллинск. политехн. ин-та. Сер. А, 1955, № 63, вып. 2, с. 3-50.

8. Фрндд ан Г. Е., Пер есленн И. М. Термическое разложение горючих сланцев в присутствии воды под давлением. - Тр. Ин-та горючих ископаемых, 1962, т. 17 , с. $60-75$. 
9. Проскуряков В. А., Жунко В. И., Сурженко Е. М., Шувалов В. И., Солов ей чи к 3 . В. Способ получения двухосновных органических кислот. Авт. свид. СССР № 140055. - Бюл. изобретений, 1961, № 15.

10. Пев зне р 3. И., Г а рц м ан Б. Б., Р умянцев а 3 . А., К а р а в а ев Н. М. Окисление среднеазиатских углей кислородом под давлением. - Докл. АН ТаджССР, 1964 , т. 7 , № 7 , c. $21-26$.

11. В и дон Б. Щелочное плавление и некоторые аналогичные процессы. - В кн.: Установление структуры органических соединений физическими и химическими методами. Кн. 2. М., 1967 , с. $234-290$.

12. $\mathrm{Ha}$ a er, F., B runer, L. Das Kohlenelement, eine Knallgaskette. - Z. Elektrochem., 1904, Jahr 10, N 37, S. 697-713.

13. Ф ук с В. Химия лигнина. Л., 1933, с. 366.

14. Alle n, J., Meharg, V. E., S chmidt, J. H. Chemistry of synthetic varnish resin. - Ind. Eng. Chem., 1934, v. 26, N 6, p. 663-669.

15. Mukher jee, P. N., L a h ir i, A. Interaction of water and coal at low temperatures. - Fuel, 1957, v. 36, N 2, p. $176-181$.

16. K a sehagen, L. Action of aqueous alkali on a bituminous coal. - Ind. Eng. Chem., 1937, v. 29 , N 5, p. $600-604$.

17. Космачева Т. Г., Агабеков В. Е., Мицкевич Н. И., Коноплян н и к Н. М. Пути образования газообразных продуктов при окислении диметиловых эфиров алифатических дикарбоновых кислот. - Изв. АН БССР. Сер. хим. н., 1971 , № 6 , с. $35-39$.

Ннститут химии

Академии наук Әстонской ССР
Поступила в редакцию $21 /$ IV 1978

\title{
R. VESKl, Jevgenia BONDAR, A. FOMINA
}

\section{VESINIKU TEKKEST SAPROPELIITIDE OKSUDEERIVA DESTRUKTSIOONI KORRAL}

Kukersiidi orgaanilise aine oksüdeerival destruktsioonil temperatuuril $175-270{ }^{\circ} \mathrm{C}$ molekulaarse hapniku rõhu all leelise vesilahuses eraldub gaasifaasi märgatavas koguses vesinikku. Sama, kuid tunduvalt vähemal määral toimub leelise vesilahuse toimel inertgaasi rõhu all. Eralduva vesiniku kogus on suurem termilișel destruktsioonil eralduva vesiniku kogusest.

\author{
R. VESKI, Eugenia BONDAR, A. FOMINA
}

\section{ON THE FORMATION OF HYDROGEN BY THE OXIDATIVE DESTRUCTION OF SAPROPELITES}

By the oxidative destruction of the organic matter of kukersite with molecular oxygen in alkaline aqueous medium under pressure, a considerable amount of free hydrogen is evolved. The same is observed by the oxidation in non-alkaline medium and also in alkaline aqueous medium under the pressure of inert gas, but the amount of hydrogen evolved is considerably smaller. In all the cases the amount of hydrogen evolved is greater than that evolved by thermal destruction at the same temperature. 